\title{
Dimensões da relação estética na obra fotográfica de Cao Guimarães $^{1(*)}$ \\ Dimensions of aesthetic relation in the photographic work of Cao Guimarães
}

\author{
Benjamim Picado ${ }^{2}$
}

Consuelo Lins $^{3}$

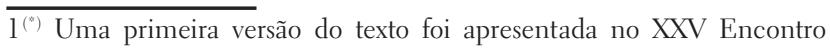
Anual da Compós, na Universidade Federal de Goiás, em junho de 2016. Somos gratos ao GT "Comunicação e Experiência Estética" pelas questões e vivos debates suscitados por nossa exposição e a Thales Vilela Lelo (responsável pela relatoria de nosso texto), por suas cuidadosas observações, sugestões e críticas, que auxiliaram no aperfeiçoamento do texto até sua forma atual.

${ }^{2}$ Doutor em Comunicação e Semiótica (PUC-SP). Professor do Departamento de Estudos Culturais e Mídia e do Programa de PósGraduação em Comunicação da Universidade Federal Fluminense (UFF). E-mail: jbpicado@hotmail.com

${ }^{3}$ Doutora em Cinema e Audiovisual pela Universidade de Paris 3. Professora titular da Escola de Comunicação e docente permanente do Programa de Pós-Graduação em Comunicação da Universidade Federal do Rio de Janeiro (UFRJ).. E-mail: consuelolins@gmail.com 
Resumo: analisaremos aqui algumas séries fotográficas do artista mineiro Cao Guimarães considerando os padrões de interação sensível promovidos por sua obra, em quadros pragmáticos da experiência estética da fotografia. A "relação estética" será identificada tanto com atitudes e regimes sensoriais que originam a obra quanto na interação com um potencial apreciador. O corpus desse estudo compreende Paisagens reais - homenagem a Guignard (2009), Úmido (2015), Plano de voo (2015) e Steps (2015) e salienta aspectos que conectam cada série com a experiência estética suscitada por suas fotografias.

Palavras-chave: fotografia; atitude estética; experiência estética; Cao Guimarães.

Abstract: we shall analyze the photographic work of Cao Guimarães considering the patterns of sensible interactions eluded by his artworks, in the pragmatic context of the aesthetic experience of photographs. The "aesthetic relation" is hereby identified with sensory attitudes and regimes that generate artworks, in interaction with potential beholders. The corpus of study consists of Paisagens reais - homenagem a Guignard (2009), Úmido (2015), Plano de voo (2015) and Steps (2015), highlighting issues that connect each series with the aesthetic experience promoted by his photographs.

Keywords: photography; aesthetic attitude; aesthetic experience; Cao Guimarães. 


\section{Prólogo: a relação estética como estilo}

"Em tudo existe um valor de expressividade, uma excelência ontológica, uma dignidade existencial. Uma folha que cai é tão expressiva quanto o beijo fatal no fim de qualquer novela, o ruído do vento tão musical quanto a performance de uma cantora lírica.” ${ }^{4}$ Essa afirmação do cineasta, fotógrafo e artista visual Cao Guimarães traduz com precisão algo que está, de certo modo, na base de toda a sua produção desde o início de sua trajetória artística nos anos 1990 e se manifesta com igual potência nos dispositivos artísticos variados utilizados pelo artista em suas obras. Uma crença na existência de uma "experiência sensível" mesmo em fenômenos aparentemente inexpressivos, uma aptidão para extrair poesia de toda e qualquer realidade, para fazer arte de qualquer coisa, em qualquer canto - algo que podemos perceber em filmes de curtas e longas-metragens, fotografias e instalações.

Por lidar de modo privilegiado com o que chamamos, a partir das formulações do filósofo Jacques Rancière (2004, p. 14), de "experiência sensível”, a produção do artista mineiro constitui matéria privilegiada para pensarmos um determinado estado do debate estético acerca de fenômenos do campo da arte contemporânea e sobre processos e obras expressivas no domínio da comunicação. Nesse sentido, é importante notar o quanto estão implicadas nessa produção questões relativas não apenas à pluralidade dos meios e empregos artísticos que são próprios a cada uma das obras, mas também ao impacto sensível que elas são capazes de promover no espectador - sem falar no fato de que boa parte de sua arte nos informa sobre o tipo de sensibilidade que a guia originariamente, marcando-a na prática como um aspecto de seu estilo5.

No cenário expandido da arte contemporânea brasileira, os trabalhos de Cao Guimarães estão entre os que circulam com mais fluidez pelas galerias de arte, museus e bienais, e salas e festivais de cinema ${ }^{6}$. Exploramos anteriormente essa produção, nas interlocuções que ela propõe entre arte e documentário, na relação com

\footnotetext{
${ }^{4}$ Cao Guimarães em "Gambiarras", entrevista concedida por e-mail à Carla Zaccagnini e publicada no Catálogo da II Trienal Poligráfica de San Juan, 2009.

${ }^{5} \mathrm{O}$ conceito de “estilo" que aqui empregamos tem enraizamento em tradições da história da arte nas quais o problema da relação entre obras particulares e sua autoria, escolas e tradições culturais necessita ser estabelecido a partir de um quadro presumido (portanto, ditado por um "paradigma indiciário" da história cultural) pela sensibilidade que governa a origem e a destinação da arte: uma tal concepção do estilo atravessa uma linhagem de pensadores que vai de Heinrich Wölfflin a E. H. Gombrich, sendo particularmente sumariada em suas linhas gerais por Carlo Ginzburg (1990). Na perspectiva em que assimilamos esse problema, acrescentamos que tal horizonte sensível pressuposto na manifestação das obras é precisamente o que identificamos como seu horizonte propriamente "estético".
}

${ }^{6}$ Até o momento, dirigiu 9 longas metragens, realizou 29 curtas-metragens em vídeo ou Super-8, 6 instalações, além de diversas séries fotográficas e fotografias individuais. 
a literatura e no constante trânsito entre diversos dispositivos e domínios expressivos, problematizando a estabilidade conceitual de cada uma dessas práticas e gêneros da arte visual (LINS, 2009; 2013; 2014). Identificamos aí um modo privilegiado de trabalhar a experiência sensível como matéria artística e indicamos finalmente uma chave de leitura situada naquilo que supúnhamos ser a atitude estética deste criador, definida como uma disposição específica de sua sensibilidade, disseminada de modos variados na extensão de sua obra.

Um dos traços característicos dessa atitude é o da "suspensão" dos mecanismos sensório-motores da percepção comum, precisamente aqueles que estruturam nossa orientação sensível no contexto das ações cotidianas, algo que o historiador Jonathan Crary descreveu em Cézanne como "um pairar em um momento estendido" (CRARY, 2013, p. 277): ao menos em parte, a obra de Cao Guimarães resulta desse tipo de "conduta estética". Em trabalhos como no curta Coletivo (2002) ou na série fotográfica Paisagens reais - homenagem à Guignard (2009), o artista suspende suas inclinações automáticas diante do que o afeta e faz uma espécie de "parada" sobre uma cena, uma imagem, uma temporalidade, uma constelação perceptiva particular. Uma suspensão que permite explorações do que é muitas vezes imperceptível para nós, através de uma reorganização visual da realidade - cores, linhas, texturas, signos, palavras, formas, ritmos, movimentos, durações.

Essa disposição sensível em face da realidade se aproxima de um pensamento historicamente determinado da experiência estética tal como apresentada nos escritos de Jacques Rancière. Naquilo que o filósofo designa como sendo seu "regime estético", a arte se dissocia de toda regra específica ou fundamento, de toda a hierarquia de temas, gêneros, formas, abolindo as fronteiras entre o que é ou não do domínio da arte, assim provocando "a ruína dos cânones antigos que separavam objetos da arte daqueles da vida ordinária” (RANCIÈRE, 2004, p. 14). Esse novo tecido sensível possibilita a concepção de obras que se originam de quaisquer fontes - a forma de um objeto cotidiano, um jorro de cor, a aceleração do ritmo de um movimento corporal, o silêncio que se destaca entre as palavras de um diálogo desde que a "coisa" em questão esteja liberada de toda utilidade, de toda propriedade, de todo interesse mais egoísta.

Esse é, portanto, o horizonte estético que nos parece informar o trabalho de Cao Guimarães. Contudo, desejamos nos manter atentos a essa aisthésis inscrita em sua obra, trabalhando o gesto artístico que a constitui, mas agora partindo da dimensão "pragmática” na qual sua obra emerge para seus espectadores - portanto, sempre implicada por uma certa relação promissora com formas ou padrões especiais 
dos regimes de sua receptividade. Trata-se de uma compreensão de seu trabalho que se exercita pelo efeito que ele suscita em um espectador suposto por essa poética das insignificâncias.

No sentido com o qual pensamos esse problema, dois movimentos são importantes, o metodológico e o empírico.

1. No plano metodológico, deslocamo-nos momentaneamente da ideia de "regime estético da arte", como elaborado no pensamento de Rancière (e vinculada a uma configuração sócio-histórica sensível que emerge no século XIX, na qual as obras de arte consolidaram um lugar privilegiado de transmissão cultural e educação sensível), para começarmos a valorizar perspectivas associadas a um viés "pragmático" da caracterização da experiência estética.

Com isso, enfatizamos aspectos dessa interrogação que situam as estruturas cognitivo-interacionais da recepção, não apenas em relação às obras de arte, mas também a outras formas de experiências. Na origem do gesto artístico de Cao Guimarães, por exemplo, está implicada uma sensibilidade que não se confunde com sua habilidade em agenciar meios e processos de criação: isso significa que sua própria aisthésis se exercita da mesma maneira que aquela do espectador comum; na base dessa mesma disponibilidade para o mundo, podemos identificar uma matriz decisiva da compreensão sobre como sua obra nos afeta sensivelmente.

Nesse contexto, despontam em nossa metodologia pensadores que circulam ainda discretamente em nosso campo de estudos, mas que aportam tradições de pensamento tão distantes de nós como a estética analítica ou a psicologia cognitiva: eles contribuem para uma renovação dessa reflexão nas duas últimas décadas do século XX, quando a dimensão estética deixou de se submeter ao domínio estrito da arte - algo que Kant já houvera indicado, ao distinguir claramente o "artístico" do "estético", mas que foi se dissolvendo a partir da interpretação romântica e hegeliana de sua teoria estética. O título do livro de Jean-Marie Schaeffer, Adieu à l'Esthétique, sugere justamente uma tal "despedida”, não da estética propriamente dita, mas daquela doutrina filosófica que se estabeleceu na esteira desse pensamento sobre a arte, definindo-a como domínio por excelência de reflexão sobre os regimes estéticos da sensibilidade.

Assimilar a estética ao artístico, ou reciprocamente, reduz-se a confundir duas atividades bem diferentes: a relação estética é um processo atencional, enquanto o termo "artístico" se refere a um fazer, assim como ao resultado desse fazer, a saber, a obra de arte. Os recursos e capacidades postas em ação em uma relação atencional e em um fazer são bem diferentes, pela razão que, enquanto estamos engajados em um processo de 
atenção, adaptamos nossas representações ao mundo, ao passo que quando nos engajamos em um fazer adaptamos o mundo a nossas representações. (SCHAEFFER, 2015, p. 41).

Esse redirecionamento de nossa análise não significa uma desconsideração das variáveis sócio-históricas do "regime estético da arte", até porque o termo "estética" nomeia para Rancière tanto esse terceiro regime da arte (o "ético" e o "representativo" são os primeiros) quanto as "formas da experiência sensível" - formulação central de sua concepção de política. Rancière participa dessa renovação da reflexão estética não vinculada exclusivamente aos fenômenos da arte, já que ele as define como uma forma de "sensorialidade", entre outras. Contudo, é a essa sensorialidade artística que ele tem se dedicado com afinco nos escritos dos últimos vinte anos. A "atitude estética" dos indivíduos ordinários não é foco de interesse do filósofo, e sim esse tipo de disposição sensível nos indivíduos ordinários que são personagens centrais dos romances, filmes, poesias e outras obras de arte que ele analisa.

Por outro lado, o pensamento de Schaeffer pode contribuir para especificar melhor os modos pelos quais Cao Guimarães ativa, antes mesmo da criação de suas obras, uma experiência estética desvinculada dos fenômenos artísticos - uma maneira de perceber e de ser afetado pelas coisas do mundo que pode acontecer potencialmente em qualquer momento, com qualquer pessoa.

Em perspectiva cognitivista, o que chamamos anteriormente de "suspensão" ou "relaxamento" dos vínculos sensório-motores da percepção comum produz uma modalidade de "atenção estética" que é resultante da seleção de "aspectos" - por seu turno, caracterizando um tipo de sensibilidade distinto daquele que orienta os regimes standard da atenção perceptiva. Nos dizeres de Schaeffer, isso implica reconhecer que a atitude estética emprega recursos genéricos da atenção perceptiva, mas a partir de "estratégias atencionais" distintas daquelas nas quais conjugamos ordinariamente o mundo: por exemplo, ao avistarmos uma tempestade prenunciada por pesadas nuvens no horizonte, podemos nos manter concentrados nos aspectos de materialização sensível desse fenômeno natural - a forma e espessura das nuvens, o modo e a velocidade de seu movimento com o vento, o contraste de cinzas -, dissociando-as portanto da precipitação chuvosa que elas implicam intelectualmente.

Embora o pensamento de Schaeffer possa efetivamente se limitar ao que Cesar Guimarães (2006, p. 20) intui como "um estudo descritivo da experiência estética", desprovido de expectativas do que essa experiência "venha trazer à sensibilidade, aos universos imaginários e às práticas cotidianas dos seus fruidores”, 
ele aqui pode nos ajudar a esmiuçar esse momento anterior às criações artísticas - o que no caso de Cao Guimarães pode ser inferido a partir de boa parte de seus trabalhos. O que nos parece importante frisar é a ênfase de Schaeffer na propriedade "relacional" da experiência estética e no fato de que aquilo que ela implica não é absolutamente a natureza do objeto, "uma propriedade interna das coisas", e sim "a atitude que se adota diante delas" - seja um fenômeno qualquer ou uma proposição da arte. Para o filósofo, "a vida de todo o dia é uma fonte permanente de momentos de atenção estética [...] pois a epifania se constitui sempre no e através do encontro entre um objeto e um indivíduo" (SCHAEFFER, 2000, p. 16).

Em boa medida, a reflexão de Schaeffer reitera questões sobre a "relação estética" que já compunham, por sua vez, o pensamento de seu grande mestre Gérard Genette: em especial, chamamos atenção para o modo como este identifica o lugar das obras de arte no centro da interrogação estética, para além daquilo que define tradicionalmente os variados modos de existência desses objetos. Mesmo mantendo a obra de arte no centro de suas investigações, Genette faz a questão estética ficar implicada pelos regimes da atenção perceptiva mobilizados pelas obras, já que essa atenção é traço originário de toda relação estética, seja com a arte ou com a natureza.

2. O segundo movimento que propomos aqui é de natureza empírica e concerne ao recorte que fazemos no corpus integral da produção artística de Cao Guimarães. No conjunto de sua obra, fixamo-nos nas séries fotográficas mais recentes que representam essa sensibilidade que seus trabalhos partilham com um potencial apreciador: são os casos de Paisagens reais - homenagem a Guignard (2009), Úmido (2015), Plano de voo (2015) e Steps (2015). Identificamos aí um conjunto de temas e opções plásticas que resulta do modo como a fotografia instaura regimes pragmáticos da interação e da atenção perceptiva qualificáveis como próprios a uma experiência estética.

As modalidades estéticas manifestas em sua obra possuem uma dupla fonte, que nos interessa simultaneamente: primeiramente, implicam aquilo que a obra desse artista nos oferece como seus próprios modos de perceber - governados que são por essa preferência por aspectos fugidios e insignificantes das coisas; em seguida, elas também nos auxiliam a pensar, sob nova luz, certas questões perenes da reflexão sobre meios e processos no campo da arte - especialmente no caso da fotografia, assombrada por um discurso que a identifica com uma imanência "transparente" ou “indexical” de significação, derivadas da natureza de seu dispositivo de visualização.

Outra maneira de formular essa duplicidade afeta o modo como a disponibilidade sensível para um mundo das insignificâncias se converte em marca estilística do trabalho de Cao Guimarães: poder-se-ia supor que tal vindicação de 
sua aisthésis não se separe facilmente de sua manifestação em "obras de arte" - com todo o peso que a ontologia desses objetos acarreta para uma discussão sobre o estilo, assim o confundindo com os traços da obra; em nosso caso, contudo, pretendemos fazer essa relação entre "estilo" e "obra" implicarem mais fortemente a necessária mediação estética que as governa, de modo a nivelar a realidade dos objetos artísticos com a disponibilidade sensível que preside sua origem, assim como seus efeitos. Em suma, compreendemos que a obra de Cao Guimarães é mobilizada por uma receptividade sensível que não se separa arbitrariamente de um regime de atenção próprio a uma experiência estética.

\section{Fotografia em diálogo com uma memória sensível em forma de pintura}

Comecemos com a série fotográfica de 2009 intitulada Paisagens reais homenagem a Guignard, que integrou a exposição Passatempo, exibida em 2012 na Galeria Nara Roesler (SP). São fotografias feitas em uma manhã nublada em Belo Horizonte, quando Cao Guimarães olhou pela janela de seu apartamento, situado no alto de uma colina, vislumbrando fragmentos de topos de prédios e igrejas atravessando as nuvens. Pegou sua câmera e registrou imagens que evocam a série pictórica Paisagens imaginantes, do pintor Alberto Guignard (1896-1962), nascido em Nova Friburgo, estado do Rio, mas radicado em Minas Gerais, onde desenvolveu a quase totalidade de sua produção artística.

Em Paisagens reais, a sensibilidade convertida em gesto artístico de Cao Guimarães reflete um aspecto da arte como promotora de uma experiência estética com o mundo: esse sentido artisticamente derivado da aisthésis é construído nas fotografias não apenas pelo título da série visual ou pela tópica da paisagem, mas sobretudo pelas relações que transparecem no recurso que Cao Guimarães faz ao meio fotográfico para se reportar às visões pictóricas de Guignard.

Emerge dessa combinação entre sensibilidade e recursos artísticos um particular vislumbre revelador, um tipo de visão diáfana da natureza em que as paisagens - assim como nas telas de Guignard - "quase se desfazem num vapor que é tanto fundo quanto superfície” (MAMMI, 2012, p. 297). Nessa perspectiva, a fotografia constitui-se em vetor através do qual as composições do pintor são restituídas a uma sensibilidade de primeira ordem - aquela de um olhar formado pela experiência das obras de arte, que o faz apreender no acaso de uma manhã nublada o aspecto de uma visão, de uma aparição reveladora que traduz uma memória sensível, fruto da "educação estética” de Cao Guimarães. 

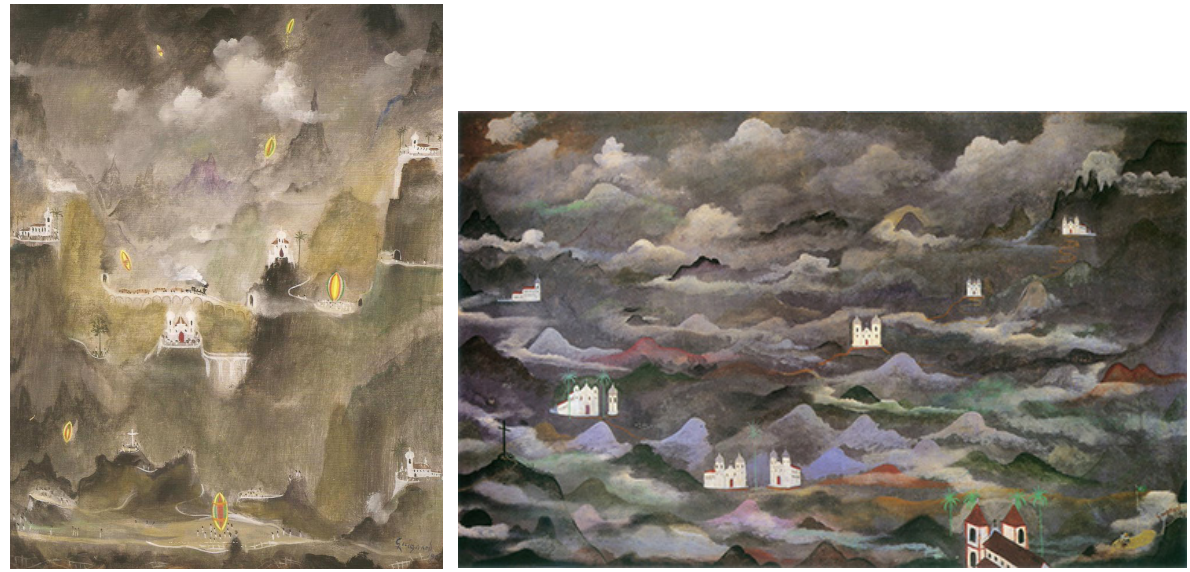

Figuras 1 e 2: Alberto da Veiga Guignard, Noite de São João (1961). In: Arte na escola (http:// artenaescola.org.br/midiateca/publicacao/?id=58745) e Paisagens imaginaria noturna (1950). In: Virus da Arte \& Cia (in: http://virusdaarte.net/guignard-as-paisagens-e-as-igrejas/).
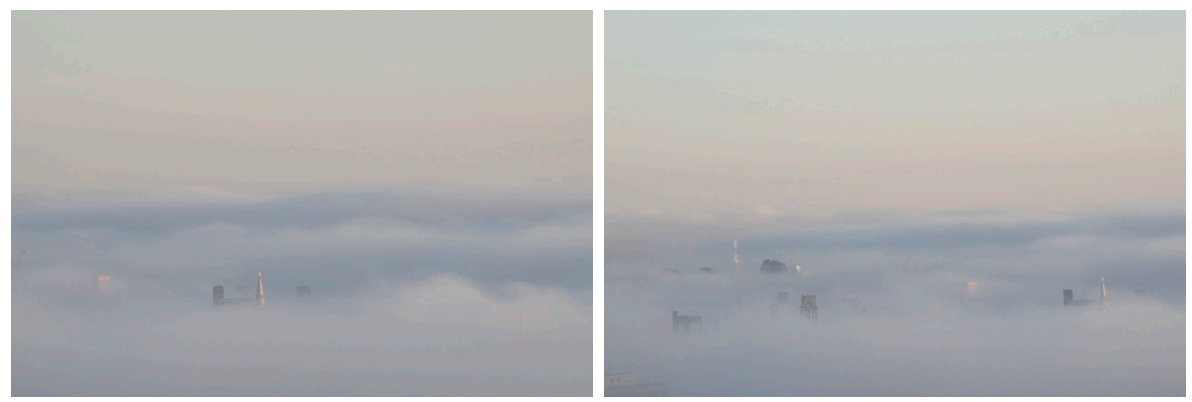

Figuras 3 e 4: Fotografias da série Paisagens reais - homenagem a Guignard (2009), de Cao Guimarães. Série de 7 fotografias - $52 \times 80 \mathrm{~cm}$ cada.

Essa comunhão entre duas séries artísticas reflete a afirmação de Heinrich Wölfflin (recordada por E. H. Gombrich), de que "todas as pinturas devem mais a outras pinturas do que à observação direta" (WÖLFFLIN apud GOMBRICH, 1995, p. 340). Ou seja, a visão é formada também por uma memória sensível que nos faz ver o mundo através dos trabalhos artísticos que nos tocaram. Ao comentar essa mesma passagem de Wölfflin, Carlo Ginzburg lembra que o próprio Gombrich demonstrara "brilhantemente como Constable via a paisagem inglesa através dos quadros de Gainsborough, e Gainsborough através dos quadros de Ruysdael e dos pintores holandeses em geral" (GINZBURG, 1990, p. 86).

Do mesmo modo, Paisagens reais é uma visão da "natureza" que se reporta não apenas aos lugares fotografados, mas às Paisagens imaginantes: a série pictórica 
de Guignard - em que enxergamos igrejinhas, casas, e pequenas cidades suspensas em um voo imaginário em meio a nuvens e montanhas mineiras -forneceu a Cao Guimarães um modelo da sensibilidade para a visão que emergira de sua janela numa certa manhã.

Sem supormos que tal interação seja apenas como um "diálogo consciente entre artistas", avaliamos essa presença de Guignard como um aspecto da estruturação sensível do mundo que Cao Guimarães põe em ação intuitivamente ao confrontarse a uma visão da natureza. Em outros termos, é a sensibilidade do pintor expressa na série que se apresenta como chave através da qual o fotógrafo põe em jogo seu tesouro sensorial, em face do mundo.

O que se descortina daí ilustra perfeitamente a caracterização que certas correntes filosóficas das teorias estéticas do último século fizeram sobre a componente "sensível" dos processos artísticos: ela nos faz recordar a lição de John Dewey (1985, p. 99) de que "o artista incorpora a si próprio a atitude de quem percebe, enquanto trabalha”; ou quando Paul Valéry (1999, p. 181-182) insiste que há na busca artística "um não sei que pressentimento das reações externas que serão provocadas pela obra em formação".

A obra de Cao Guimarães é um belo exemplo de como a arte põe em cena uma sensibilidade para o mundo, constituída, entre outros elementos, pelo contato do artista com outras obras. Em suma, referida pelo nome de Guignard, esse caráter esvoaçado da natureza pintada incorpora-se de algum modo à fotografia, um meio que tão bem responde às casualidades visuais que habitam a produção desse artista: pois, ao abrir a janela de seu quarto, ele se depara não apenas com um mundo todo nu, mas também com o atravessamento que nele se faz da memória sensível das séries pictóricas do pintor friburguense.

Por outro lado, de modo mais importante, esse encontro é convertido em chave estilística através da qual Cao Guimarães construirá sua remissão a Guignard como um sinal de comunidade entre suas respectivas sensibilidades. Nesse último aspecto, como dissemos no início do texto, essa relação que o fotógrafo instaura entre "modos de perceber" não é apenas um operador das relações da fotografia com seu espectador possível, mas constitui igualmente uma marca de sua própria assinatura artística - em suma, de seu estilo.

Ao avançarmos sobre outros segmentos da obra fotográfica de Cao Guimarães, exploraremos esses pontos relativos a uma dinâmica atencional do regime específico da fixação de sua percepção sobre seus objetos, aspecto que guia a sensibilidade reclamada por suas fotografias, enquanto traço estilístico: através desses 
outros momentos de sua obra, dirigimo-nos para o problema de como essa iconografia trabalha com o sentido esteticamente relevante da materialidade das superfícies, da plasticidade implicada nos modos de sua impregnação sensível e no sentido de uma possível narratividade que se depreende das configurações que ele recorta em seus encontros casuais com o mundo.

\section{Fotografia como arte da superfície}

Motivado por um livro que decidiu organizar sobre seu percurso artístico ao completar 50 anos de vida, Cao Guimarães revisitou, entre 2014 e 2015, seu arquivo de imagens e escritos - particularmente o que ficou de fora, os restos de filmes não editados, fotografias não exibidas, esboços de textos não finalizados. Deparou-se com trabalhos que tinham "uma intenção estética, um olhar que, mesmo um pouco inconsciente, estava atento a uma identidade formal"7 - trabalhos que estavam em hibernação, à espera de um gesto que lhes desse nova vida. Além do livro, essa retomada dos arquivos pessoais gerou a exposição Depois, apresentada em 2015 na galeria Nara Roesler (SP).

As séries fotográficas que analisaremos a seguir fazem parte dessa exposição, sendo fruto de experimentações menos visíveis na trajetória pública do artista, realizadas em paralelo a outros gestos fotográficos mais conhecidos. São fotografias que evocam um imaginário e uma poética menos realistas do que aqueles contidos em trabalhos como Gambiarras, Espantalhos, Paquerinhas, Campo cego. Nessas séries - “inventários do mundo”, como define o artista - há algo de muito preciso nas imagens a capturar de imediato a atenção do espectador: agora, um pouco como vemos em Paisagens reais (talvez a única série anterior do artista que se aproxima dessas novas imagens), é a totalidade do espaço enquadrado que solicita nossa atenção, e a ausência de profundidade de campo - aspecto formal de todas as fotografias - é fator fundamental para esse modo de apreensão. Algumas imagens possuem formas mais abstratas, outras são saturadas de marcas e sinais, lembrando pinturas expressionistas. Em todas elas, descobrimos uma verdadeira "arte da superfície", pela qual Cao Guimarães nos oferece suas visões e impressões de um chão que desconhecíamos ou que talvez não conseguíssemos ver. Nesse contexto, ele gesta os elementos de seu estilo, como derivados de um certo modo de se colocar sensivelmente em face de seus temas preferenciais, como exploramos na seção anterior.

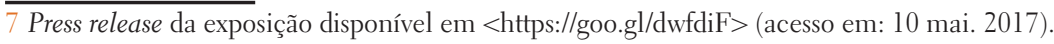


Olhar para o chão e identificar na superfície em que pisamos - e que mal enxergamos - uma infinidade de possibilidades poéticas e uma miríade de eventos sensíveis (inscrições de pegadas humanas, rastros de animais, manchas de umidade) é deparar com "esplendores transitórios" a nos convencer de que "a beleza está em todo lugar" e de que "tudo é matéria própria à ficção" (WOOLF, 2007, p. 31, 79), pois tudo é matéria própria à arte. Olhar para o chão e intuir o que o artista chama de "microdramas da forma", compor com o quadro da câmera, recortar a superfície sem afetação nem complicações. Em nenhuma dessas fotografias, o artista utiliza outra coisa senão sua câmera fotográfica digital; tampouco manipula as imagens na pós-produção para além de uma ligeira correção de cor. A potência expressiva dessas séries, a evocação de um imaginário pictórico e o registro documental acontecem exclusivamente no momento da tomada. Se nas Paisagens reais o que se fazia presente era uma memória sensível impregnada pelas visões da paisagem mineira de Guignard, agora são as próprias composições dessas outras séries que evocam uma memória sensível formada por valores pictóricos da pintura abstrata.

À primeira vista e a certa distância, a série Steps (de 2015) evoca imagens de pinturas rupestres gravadas em rochas de variados tons de cinza; inscrições arcaicas nas paredes de alguma caverna perdida, ora deixando ver formas de uma espécie de peixe pré-histórico, ora imagens de objetos circulares, ora desenhos menos identificáveis. Com a aproximação, reconhecemos inscrições bem mais prosaicas de solas de sandálias de borracha e sapatos diversos, além de pedaços de fita adesiva, ou contornos de discos de CD. Talvez imagens de calçadas recém-construídas, marcadas por quem passou por ali ainda com o cimento fresco.

Ainda que saibamos que essas fotografias reportam-se a uma lona preta, coberta de pó de cal, marcada de pegadas dos trabalhadores de uma obra em construção, há nelas certa indeterminação, uma incerteza acerca daquilo que efetivamente tratam. Texturas, traços formais, composição, materialidades, tudo isso convoca um imaginário mais vinculado a valores pictóricos do que referenciais; ao mesmo tempo, as marcas das solas de calçados fornecem às imagens uma dimensão mais realista. Se nada mais sugerisse que essas imagens são fotografias diretas do mundo, restariam essas solas triviais e populares a assombrar essas superfícies, tornando mais complexa a experiência do espectador. 

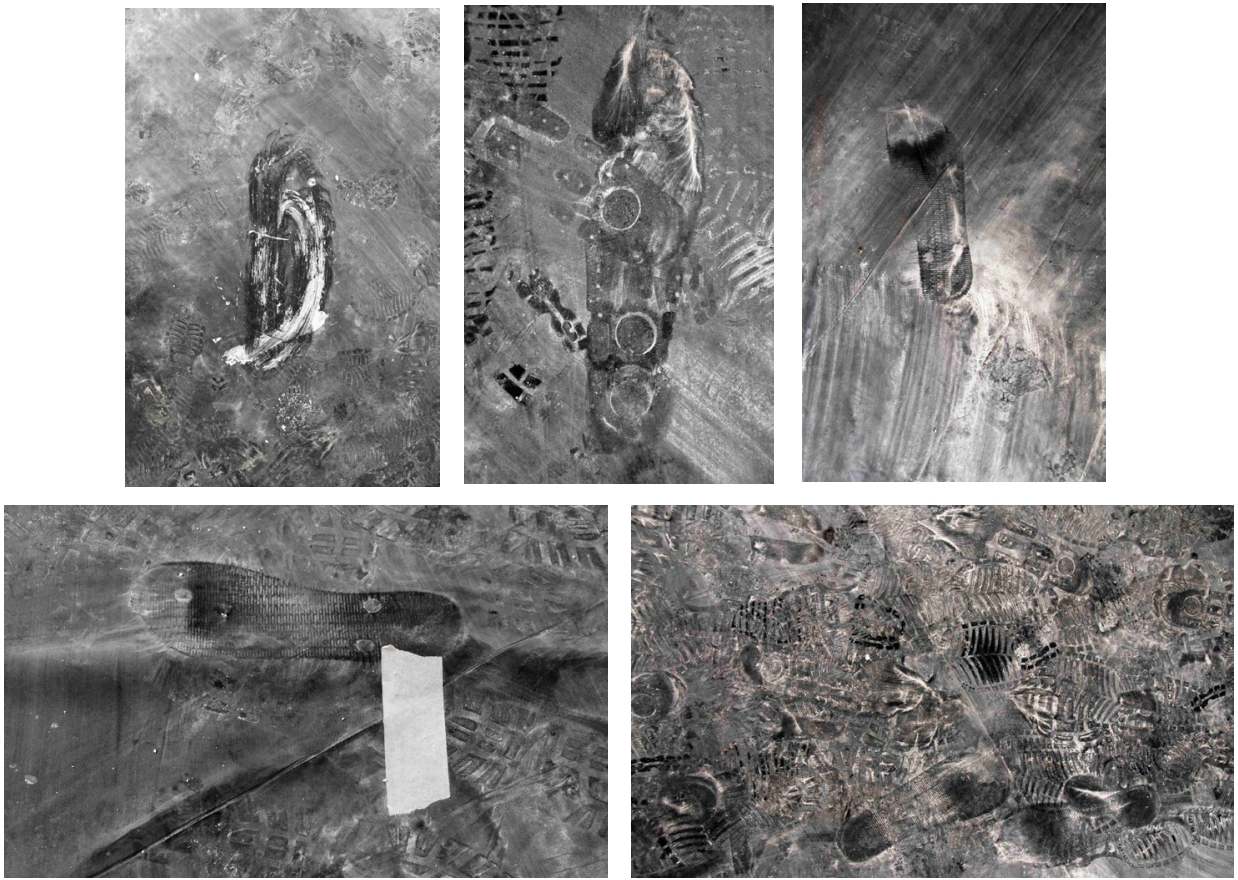

Figuras 5 a 9: Fotografias da série Steps (2015), de Cao Guimarães. Série de 15 fotografias, $50 \times 75 \mathrm{~cm}$ cada.

Por outro lado, a série fotográfica resulta de uma atenção estética a matérias afetadas por alguma força mais ou menos invisível, resultando dessa impregnação uma configuração visual para a qual o olhar do artista se detém, do ponto de vista de sua potencial plasticidade: tal concentração da percepção é um elemento da sensibilidade do artista, conduzindo operações pelas quais ele retira esse evento de sua aparente casualidade, para inscrevê-lo a uma possível experiência estética. Assim, a atenção que origina essas imagens atesta a indissociável economia em que se jogam as dinâmicas atencionais da percepção comum e as estruturas de uma intencionalidade artística que transfigura o cotidiano em plasticidade sensível.

Emprego aqui a atenção como simétrica da intenção: a produçã̃o de um objeto - por exemplo, uma obra de arte por um ser humano procede sempre de uma intenção, em seu sentido ordinário (ou forte) do termo, e a recepção de um objeto, mesmo natural e portanto em princípio não intencional neste primeiro sentido, procede de uma atividade que se poderia qualificar como intencional, no sentido husserliano (e searleano) [...]: toda atividade perceptiva ou cognitiva é intencional nesse sentido. (GENETTE, 2010, p. 412-413) 
Nos termos de uma dinâmica intencional, não podemos separar o gesto artístico com o qual Cao Guimarães identifica formas visuais e padrões plásticos em um sítio de construção civil, de um lado, do sentido propriamente estético de seu primeiro encontro aparentemente casual com uma superfície de lona coberta de pó de cal e marcada de objetos de todo tipo. De um ponto de vista estético, a dimensão artística ou intencional que gera suas obras deriva necessariamente desse gesto pelo qual os "aspectos" notados no mundo (superfícies, marcas, pegadas) se convertem em "propriedades plásticas" (formas, objetos, efeitos): a origem do gesto que molda essa plasticidade enquanto obra não pode situar-se exclusivamente na intencionalidade artística, já que implicaria desconsiderar que o artista faz seus encontros sensíveis com o mundo nas mesmas condições de partida de indivíduos ordinários.

Não é igualmente o caso supormos que o atributo estético seja, de alguma maneira, identificável como intrinsecamente próprio a certos tipos de objetos sensíveis (obras de arte ou estados da natureza): se a atenção condiciona a conduta estética, então essa qualidade experiencial de um encontro sensível com o mundo somente pode ser concebida como emergindo de nossos estados mentais, em suma, do exercício mesmo da atencionalidade enquanto disposição sensível. O próprio Genette (2010, p. 414) nos lembra de que “os 'objetos estéticos' são primeiramente objetos atencionais, quer dizer, objetos da atenção". Uma vez mais, no caso de Steps, isso significa valorizar na série fotográfica os regimes estéticos da atenção como antecedendo a intencionalidade artística, já que a realidade de sua obra deriva desses encontros de sua sensibilidade com uma realidade aparentemente insignificante.

Algo assim acontece na série Úmido, formada por quatro fotografias, cada uma das superfícies retangulares exibindo (em variados tons de bege) folhinhas coloridas, algumas poucas formigas, restos de minhoca, dentre outros microelementos mais claramente realistas. De um lado, o impacto sensível dessas fotografias é menos dramático do que em Steps: as marcas parecem mais efêmeras, evanescentes, submetidas ao tempo (a umidade eventualmente secará, as folhas poderiam voar), mas ainda assim, como em Steps, a dimensão referencial é menos relevante do que o efeito plástico e sensível que as imagens excitam.
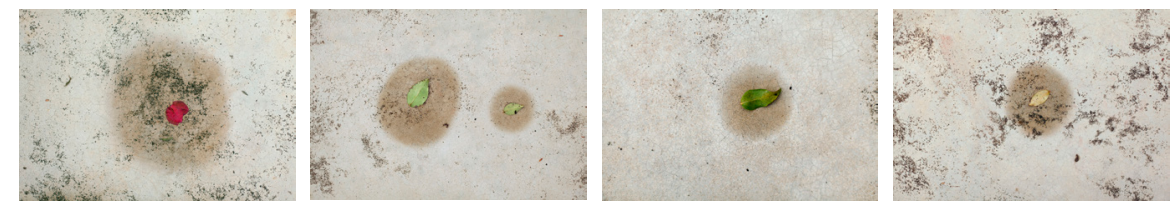

Figuras 10 a 13: Fotografias da série Úmido (2015), de Cao Guimarães. Série de 4 fotografias, $90 \times 60 \mathrm{~cm}$ cada. 
O espectador é uma vez mais convidado a explorar a superfície do quadro, a divagar sobre essa materialidade, a se perguntar "do quê" essa foto é afinal imagem. É na duração que ele perceberá o quanto de realidade está impregnada nessas imagens planas, desprovidas de profundidade e dotadas de uma composição plástica que novamente nos aproxima da arte moderna - percepção acentuada pelas pequenas rachaduras do fundo da imagem que se assemelham a craquelês (ranhuras provocadas em pinturas antigas pela passagem do tempo).

É na vibração entre abstração pictórica e registro documental que encontramos o fenômeno da "aspectualidade", fonte de uma experiência estética: em Úmido, os halos que indexam umidade, a recorrência das folhas configuradas no centro dos planos, as formigas que passeiam pela superfície e as ranhuras no fundo da imagem são todos aspectos do mundo acionados pelo regime perceptivo do artista, provocando sua atuação criativa. Tais aspectos emergem a partir das dinâmicas relacionais da percepção comum.

O tema do "aspecto" é frequente em várias correntes da estética contemporânea: segundo Genette, por exemplo, a atenção própria à experiência estética é um tipo de ocorrência da percepção não guiada pelo pressuposto do interesse ou da determinabilidade cognitiva de seus objetos. Essa atenção desinteressada da percepção é de natureza predominantemente "aspectual", própria de uma relação perceptiva na qual salientam-se determinadas propriedades mobilizadas pela interação sensível com o mundo.

Em Úmido, tal "aspectualidade” governa um tipo de disposição sensorial em face da imagem, mais dirigida a regimes particulares da atenção perceptiva do que ao reconhecimento de temas ou assuntos da representação. Nesses termos, Cao Guimarães nos coloca diante de um modo de sentir e de inquirir cada superfície das fotografias: as marcas, os objetos, as inscrições impregnadas em cada imagem refletem uma dimensão da experiência estética, situada na receptividade sensível (tanto do artista quanto de seu apreciador), definida por uma capacidade de selecionar, destacar e fazer funcionar sensivelmente aspectos perceptivos (por mais insignificantes que sejam), antes mesmo da percepção operar sobre esses objetos - na perspectiva de sua determinação semântica, referencial ou instrumental.

Segundo Schaeffer (2015, p. 51-52), esse é um traço da experiência estética definido por um tipo de engajamento perceptivo próprio ao regime específico de nossa atenção sensorial. 


\begin{abstract}
A hipótese segundo a qual a atenção em regime estético se distingue de modo significativo da atenção comum é dificilmente contestada, salvo por aqueles que sustentam que não existe orientação especificamente estética da atenção, mas unicamente objetos específicos - a saber, as obras de arte sobre os quais exercemos nossa atenção comum. Já mostrei a que ponto esta posição é contra-intuitiva [...]. Podemos, de fato, mostrar que [...] quando nos engajamos em uma experiência estética, nós orientamos nossa atenção de forma bastante singular. É a constante conjunção de alguns tipos de mudança e o fato de que eles convergem, assim reforçandose mutuamente que justifica que falemos de um determinado modo da experiência [...]. Ora, a atenção em modo estético consiste precisamente em uma tal estratégia específica.
\end{abstract}

Nesse sentido, a relativa indeterminação motivada pelas imagens dessa série constitui-se como fenômeno de base da experiência estética que o espectador obtém, assim que observe sua própria atenção sensível. Outra característica que se destaca no modo como as séries fotográficas dialogam com a capacidade receptiva do espectador - e que diz respeito à direção da apreensão e da apreciação estéticas dos efeitos plásticos da pintura ou da fotografia - tem a ver com uma espécie de potencialidade narrativa originada da organização em série dessas imagens. Ao examinarmos outro segmento da produção fotográfica de Cao Guimarães, pretendemos identificar como se articulam a atenção estética e aquilo que aqui chamaremos de "imaginação narrativa”.

\title{
Outra indexicalidade fotográfica: da ontologia à narratividade
}

Consideremos a série Plano de voo (2015): encontramos um conjunto de pegadas de pássaros deixadas sobre a areia, configurando (especialmente por seu modo de exposição), uma visão de conjunto que valoriza as eventuais conexões entre as quatro imagens que a constituem. Contudo, algo emerge dessa série, nos fazeendo pensar sobre o potencial humor dessas formas infantis e desse plano de voo enlouquecido, reforçado pelo título da série. Nesse contexto, o que nos interessa aqui é o modo como essas imagens acionam uma imaginação narrativa do artista e do espectador.

A superfície arenosa dessas fotografias, a particular adaptabilidade que ela concede aos corpos que nela se movimentam, a forma das marcas e os sentidos configurados de seus movimentos, todos esses elementos cumprem uma função precisa, implicando uma sensibilidade que é, ao mesmo tempo, receptividade e intervenção criativa: os aspectos visuais são componentes de uma aisthésis, cujos sujeitos (espectador ou artista) capturam espontaneamente as formas no mundo. 

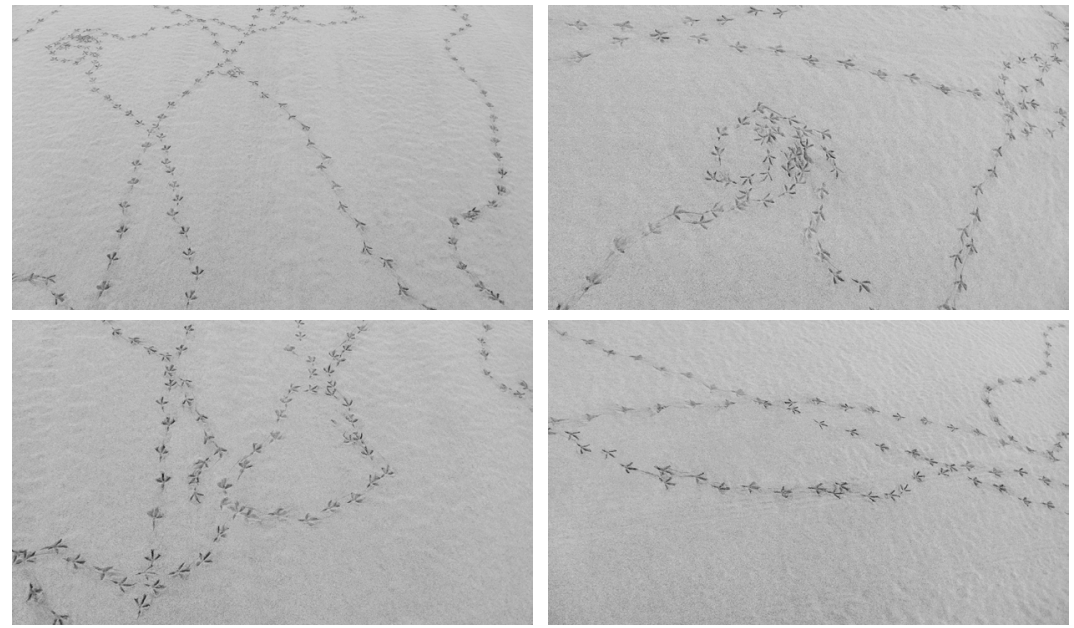

Figuras 14 a 17: Fotografias da série Plano de voo (2015), de Cao Guimarães. 4 fotografias, $70 \times 40 \mathrm{~cm}$ cada.

Essa série também problematiza características que tornam compreensível o fato de que Cao Guimarães inscreve à fotografia a dimensão de um meio artístico: entre outros aspectos, as pegadas são os exemplos mais "arcanos" da interrogação filosófica acerca dos signos indiciais, significando a presença do impregnante através de um signo necessariamente parcial de sua presença (como igualmente se pode interpretar as pegadas da série Steps). De uma maneira indireta (como sói ser com índices), as pegadas de gaivotas fazem uma reflexão sobre a própria fotografia, essa imagem constantemente "atrasada" em sua significação, sempre apreendendo todo acontecimento na sua ruína - e, nesse sentido, ilustrando, no universo das imagens, o modo de funcionamento de um "paradigma indiciário" como aquele do historiador ou do arqueólogo diante de arquivos visuais ou em sítios de antigas civilizações.

Por isso, o sujeito da experiência estética dessa série é também alguém que se interroga sobre os passos dessas criaturas, sobre sua aparente desorientação, partindo dos elementos parciais da imagem para reconstruir uma totalidade possível dessas ações. Na trilha de Carlo Ginzburg (1990, p. 151), uma dimensão da atitude estética que nos guia nos torna partes daquela linhagem dos caçadores, capazes de "reconstruir as formas e movimentos das presas invisíveis pelas pegadas na lama, ramos quebrados, bolotas de esterco, tufos de pelos, plumas emaranhadas, odores estagnados". 
O que caracteriza esse saber é a capacidade de, a partir de dados aparentemente negligenciáveis, remontar a uma realidade complexa não experimentável diretamente. Podese acrescentar que esses dados são sempre dispostos pelo observador de modo a dar lugar a uma sequência narrativa, cuja formulação mais simples poderia ser "alguém passou por lá”. (GINZBURG, 1990, p. 152)

Em tais aspectos, o trabalho de Cao Guimarães valoriza outro modo de pensar a imanência indexical da imagem fotográfica - tantas vezes referida na teoria da fotografia, ao ponto mesmo de impedir uma saída para além desse alegado "realismo" fotográfico. Em Plano de voo, a parcialidade dos índices se põe em jogo a partir de uma dinâmica de significação mais empenhada na interação que essas imagens promovem com a imaginação do espectador. Nessa série, o arranjo do tema das pegadas nos lança ao encontro da gestalt das marcas de pássaros na areia, por seu turno sugerindo um mapa da animação somática dos mesmos - implicando uma imaginação narrativa dependente dos saberes e percepções prévias que tenhamos sobre tais criaturas.

Essa dimensão potencialmente narrativa da significação visual confere aos índices um sentido raramente explorado pelas teorias da fotografia: em vez de fazer seus objetos existirem pela presumida "transparência” (WALTON, 1984) ou no “automatismo" do processo de gênese mecânica da imagem (DUBOIS, 1983), o que emana dessa particular série visual evoca as ações imaginadas das criaturas, informadas pelos signos parciais de seus caminhos sobre a superfície arenosa. O assunto da imagem, enquanto significação indexical, são acontecimentos e não entidades.

Se articularmos essa “imaginação narrativa” com os regimes da "atenção perceptiva" que inspiram Plano de voo, a relação dessa série visual com a sensibilidade que a motiva é menos oriunda da materialidade de sua apresentação e mais governada por uma espécie de protonarratividade que a fotografia instaura para a percepção. Do mesmo modo que em Steps, há aqui uma graça pela qual a fotografia inscreve a seus objetos uma função apenas consumada pela atividade perceptiva - quando inscrevemos à imagem uma suíte, plasmando narrativamente sua gestalt; e não apenas a narrativizamos, como também a qualificamos pelo riso que emerge desse voo incerto de criaturas ausentes da imagem.

Nesse contexto, o destino da significação fotográfica na obra de Cao Guimarães deve ser construído na relação com o que a curadora Lisette Lagnado (2003) definiu como "micro-descargas narrativas instauradas entre uma obra e sua recepção". Esse outro sentido da indexicalidade somente emerge na dimensão pragmática da experiência estética de sua obra: primeiramente, tal experiência 
somente pode ser examinada na dinâmica perceptiva da "atenção estética", enquanto correlação entre aspectualidade e plasticidade (a fixidez da apresentação fotográfica não nos impede de notar a vibração que emerge das dinâmicas perceptivas que ativam a imagem); em segundo lugar, suas imagens não se reportam a entidades do mundo, mas sobretudo a eventos plásticos (a impregnação das superfícies) e acontecimentos narrativos (o movimento dos seres). Em suma, é a relação entre imagem e percepção que guia a significação fotográfica, sendo esta última de ordem narrativa e dinâmica.

\section{Referências}

CRARY, J. Suspensões da Percepção. Tradução Tina Montenegro. São Paulo: Cosac\&Naify, 2013;

DEWEY, J. “Tendo uma experiência”. Tradução Murilo Otávio Rodrigues Paes Leme. In: Pensadores). John Dewey. São Paulo: Ab̉ril, 1985. p. 89-105. (Coleção Os

DUBOIS, P. L’Acte photographique. Bruxelles: Labor, 1983.

GENETTE, G. L 'Oeuvre de l'Art. Paris: Seuil, 2010.

GINZBURG, C. Mitos, emblemas, sinais. Tradução Federico Carotti. São Paulo: Companhia das Letras, 1990.

GOMBRICH, E. H. Arte e ilusão. Tradução Raul de Sá Barbosa. São Paulo: Martins Fontes, 1995.

GUIMARÃES, C. Cao. São Paulo: Cosac Naify, 2015a.

“O que ainda podemos esperar da experiência estética?". In: GUIMARÃES, C.; LEAL, B. S.; MENDONÇA, C. C. (Orgs.). Comunicação e experiência estética. Belo Horizonte: UFMG, 2006. p. 13-26.

Paisagens reais - homenagem a Guignard. 2009. Série fotográfica. Disponível em: <https://goo.gl/cEhFXo>. Acesso em: 12 dez. 2015

Plano de voo. 2015b. Série fotográfica. Disponível em: <https://goo.gl/ ¡hCCQJ>. Acesso em: 10 mai. 2016.

Steps. 2015c. Série fotográfica. Disponível em: <https://goo.gl/VjcyOr>. Acesso em: 20 abr. 2016.

Úmido. 2015d. Série fotográfica. Disponível em: <https://goo.gl/RfrnHH>. Acesso em: 15 jan. 2017.

LINS, C. "Cao Guimarães e a suspensão do tempo". In: MACIEL, K.; FLORES, L. (Orgs.). Instruções para filmes. Rio de Janeiro: +2 Produções, 2013. p. 87-93.

"Descartes como figura estética do cinema de Cao Guimarães". In: GONÇALVES, O. (Org.). Narrativas sensoriais. Rio de Janeiro: Circuito, 2014. p. 83-102. 
"Experiência sensível e vida ordinária em Cao Guimarães: uma análise das obras Ex-Isto e Passatempo". In: Anais do XXII CONGRESSO ANUAL DA COMPÓS, 22., 2013, Salvador. Anais... Salvador: UFBA, 2013.

. "Rua de mão dupla: documentário e arte contemporânea". In: MACIEL, K. (Org.). Transcinemas. Rio de Janeiro: Contracapa, 2009. p. 327-340.

LAGNADO, L. "O malabarista e a gambiarra”. In: Trópico. 2003. Disponível em: <http://p.php.uol.com.br/tropico/html/textos/1693,1.shl>. Acesso em: 18/12/2015.

MAMMI, L. O que resta: arte e crítica de arte. São Paulo: Companhia das Letras, 2012.

RANCIÈRE, J. Aisthésis. Paris: Galillée, 2011.

Le fil perdu: essais sur la fiction moderne. Paris: La Fabrique, 2015.

. Malaise dans l'Esthétique. Paris: Galilée, 2004.

SCHAEFFER, J.-M. Adieu à l'Esthétique. Paris: PUF, 2000.

. L'Éxperience Esthétique. Paris: Gallimard, 2015.

VALÉRY, P. Variedades. Tradução Maiza Martins de Siqueira. São Paulo: Iluminuras, 1999.

WALTON, K. “Transparent Pictures: on the nature of photographic realism”. Critical Inquiry, Chicago, v. 11, n. 2, p. 246-277, 1984.

WOOLF, V. O leitor comum. Tradução Luciana Viégas. Rio de Janeiro: Graphia, 2007. 